\title{
Geographical maldistribution of surgical resources in South Africa: A review of the number of hospitals, hospital beds and surgical beds
}

\author{
A J Dell, BSc, MB ChB, PhD; D Kahn, MB ChB, FCS (SA), ChM \\ Department of Surgery, Faculty of Health Sciences, and Groote Schuur Hospital, University of Cape Town, South Africa
}

Corresponding author: A J Dell (angelajdell@gmail.com)

\begin{abstract}
Background. The global burden of surgical disease has been studied to a limited extent. Despite the proven benefits of surgery, surgical services remain poorly resourced. Contributing to this global crisis is the critical lack of data regarding available resources.

Objective. To analyse the distribution of some resources necessary for the provision of surgical care. The distribution and number of surgical resources (number of surgical beds) relative to the general resources (number of hospitals and total number of beds) in South Africa were analysed.

Methods. All hospitals in the country, including those in the public and private sectors, were contacted, and the total number of hospitals, the level of care (district v. regional v. tertiary), the total number of hospital beds, and the number of surgical beds were determined. The data were analysed according to the provincial distribution and the public v. private sector distribution relative to the size of the population. Results. A total of 544 hospitals were included in the study - 327 in the public sector and 217 in the private sector. The public sector hospitals included 257 district-, 49 regional- and 21 tertiary-level hospitals. Nationally, there were 1 hospital, 187 hospital beds and 42 surgical beds per 100000 population. Gauteng Province (GP), the Eastern Cape, KwaZulu-Natal (KZN) and the Western Cape had the most hospitals and GP had the largest number of private hospitals. GP and KZN had the largest total number of beds ( $n=29181$ and $n=22889$, respectively) and number of surgical beds ( $n=7289$ and $n=4651$, respectively). GP had the largest number of private surgical beds ( $n=4837$ ). There was a marked variation in the number of hospitals, total number of beds, and number of surgical beds among provinces.

Conclusion. This study provided an estimation of the number of hospitals, total number of beds, and number of surgical beds, and showed a marked variation among provinces and between the public and private sectors.
\end{abstract}

S Afr Med J 2017;107(12):1099-1105. DOI:10.7196/SAMJ.2017.v107i12.12539

Although a significant proportion of the global burden of disease can be treated surgically, and surgical illnesses are associated with significant morbidity and mortality, surgery has to a large extent been neglected as a developmental initiative. ${ }^{[1-3]}$ In many developing countries, numerous patients who require basic surgical treatment never reach a healthcare facility, and those who do, encounter inadequate surgical resources. ${ }^{[4]}$

The full extent of the global burden of surgical disease is to a large extent unknown. It has been estimated that $>2$ billion people worldwide do not have access to the most basic surgical care. ${ }^{[5]}$ Clearly, the 'unmet surgical need' is enormous. The Lancet Commission on Global Surgery (LCGS) acknowledged that surgery should be included as a core component of any health system, and made recommendations to stakeholders with regard to funding, provision and governance of surgical care. The LCGS designed a template to be used by stakeholders when implementing a national surgical plan, and included recommendations on infrastructure (tracking the number and distribution of facilities), workforce (density and distribution of surgical, anaesthetic and obstetric specialists), service delivery (Bellwether procedures), financing and information management (robust information systems). ${ }^{[6]}$

A major contributing factor to the global crisis with regard to surgery is the lack of comprehensive data, with few studies investigating surgical infrastructure and resources. The problem is further compounded by the lack of clarity as to which metrics should be measured to assess surgical infrastructure and resources. Furthermore, many of the metrics currently available have limitations when used to assess surgical services.
The development of a surgical plan requires an analysis of the existing surgical facilities. Therefore, the aim of the current study was to analyse the number of surgical beds in each province in South Africa (SA) relative to the overall number of health facilities, i.e. the number of hospitals and hospital beds.

\section{Methods}

Study design and data collection

This study was a descriptive analysis of the overall number of hospitals, hospital beds and surgical beds in SA. SA has a dual health service, i.e. a public health service funded by the state and a private health service for patients who have health insurance or are self funded. The latter is used by $\sim 16 \%$ of the population. Public hospitals were categorised as district-, regional- and tertiary-level hospitals according to the National Department of Health (NDoH) criteria. ${ }^{[7]}$ According to $\mathrm{NDoH}$ definitions, district hospitals are staffed by family physicians or medical officers, regional hospitals are staffed by general specialists, and tertiary hospitals are staffed by general specialists and/or sub-specialists. However, there is considerable overlap, e.g. a district-level hospital may have specialists on the staff and provide specialist level of care. Clinics and so-called specialised hospitals, such as psychiatric, tuberculosis and rehabilitation facilities, were excluded, based on the assumption that limited or no surgery occurred at these facilities. Private facilities that performed day theatre surgery were included.

A list of all hospitals in SA was obtained from the Provincial DoH and cross-referenced with electronic databases of hospitals in SA 
(Medpages and hospital websites). These were cross-referenced with the NDoH hospital list from the office of the minister of health.

The Health Systems Trust provided estimates of the total number of hospitals and hospital beds for each province for comparison among the provinces. The public hospitals were grouped according to the nine provinces in SA and were subdivided into major district municipalities.

All hospitals were contacted telephonically and by email. Either the chief executive officer, superintendent or matron (in the case of district-level facility) in each hospital was contacted to obtain the relevant data. Data were collected from 1 October to 31 December 2014. Private hospital data were readily available from the Hospital Association of SA (HASA) and included extensive data on the number of hospitals, total number of hospital beds and type of beds. Private hospitals were contacted telephonically to verify these data.

\section{Ethical approval}

Permission to conduct this research was obtained from the provincial departments of health and from the individual hospitals. The research was approved by the Human Research and Ethics Committee, University of Cape Town (ref. no. HREC 515/2013, 515/2014, 515/2015) and the departmental Research Committee for the Department of Surgery, University of Cape Town.

\section{South African background}

Population estimates for 2014 were obtained from census data from Stats SA. ${ }^{[8]}$ In 2014, SA had a population of 54 million. ${ }^{[9]}$ The World Bank has designated SA as an upper-middleincome country, with a gross domestic product (GDP) of USD6 619 per capita. The total GDP for 2014 was USD350 billion, with an estimated growth rate of $1.5 \% \cdot{ }^{[9]} \mathrm{SA}$ has been divided into nine provinces: the Eastern Cape (EC), the Free State (FS), Gauteng Province (GP), KwaZulu-Natal (KZN), Limpopo Province (LP), Mpumalanga Province (MP), North West (NW), the Northern Cape (NC) and the Western Cape (WC). These have been subdivided into 52 district municipalities. ${ }^{[7]}$

\section{Data analysis}

The total number of hospitals and public and private hospitals in each province were documented. Similarly, the total number of hospital beds and surgical beds in the public and private sector in each province were documented. Using the population estimates for 2014, the number of hospitals and hospital/ surgical beds per 100000 population were calculated. Based on the estimation that $16 \%$ of the population have medical insurance and make use of the private sector, ${ }^{[10]}$ the number of public hospitals and beds per 100000 uninsured population and the number of private hospitals and beds per 100000 insured population in each province were calculated.

\section{Results}

\section{Total number of hospitals}

A total of 544 hospitals were included in the study, of which 217 were private

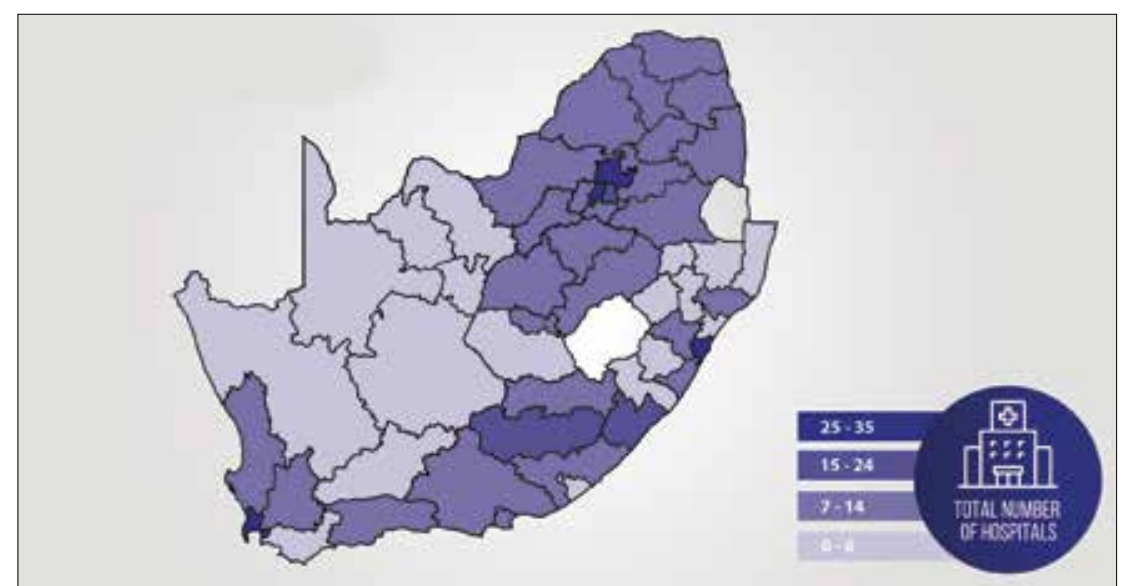

Fig. 1. Provincial distribution of total number of hospitals in South Africa according to district municipality.

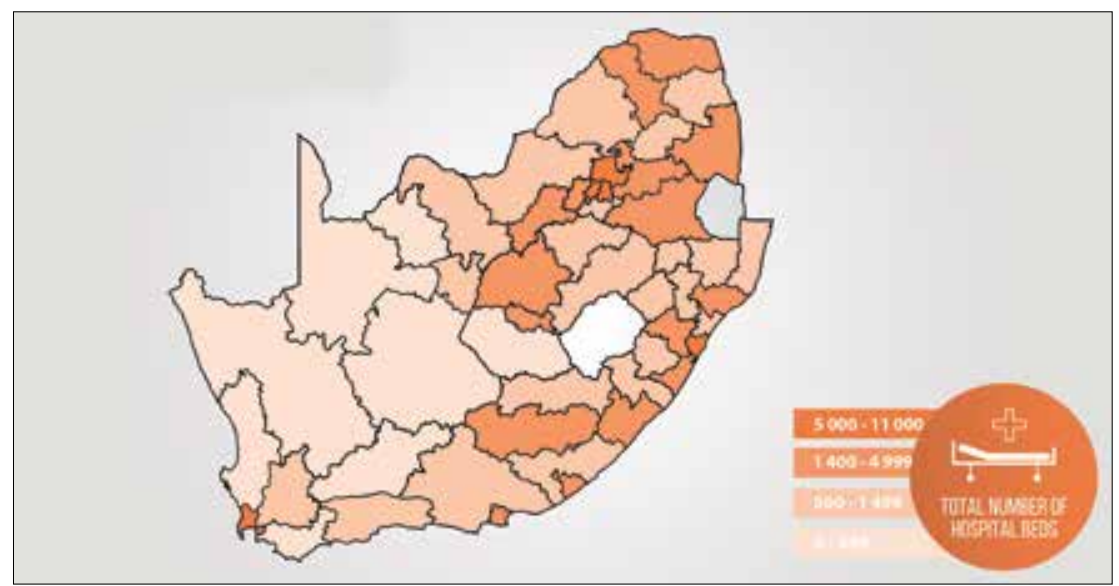

Fig. 2. Provincial distribution of total number of hospital beds in South Africa according to district municipality.

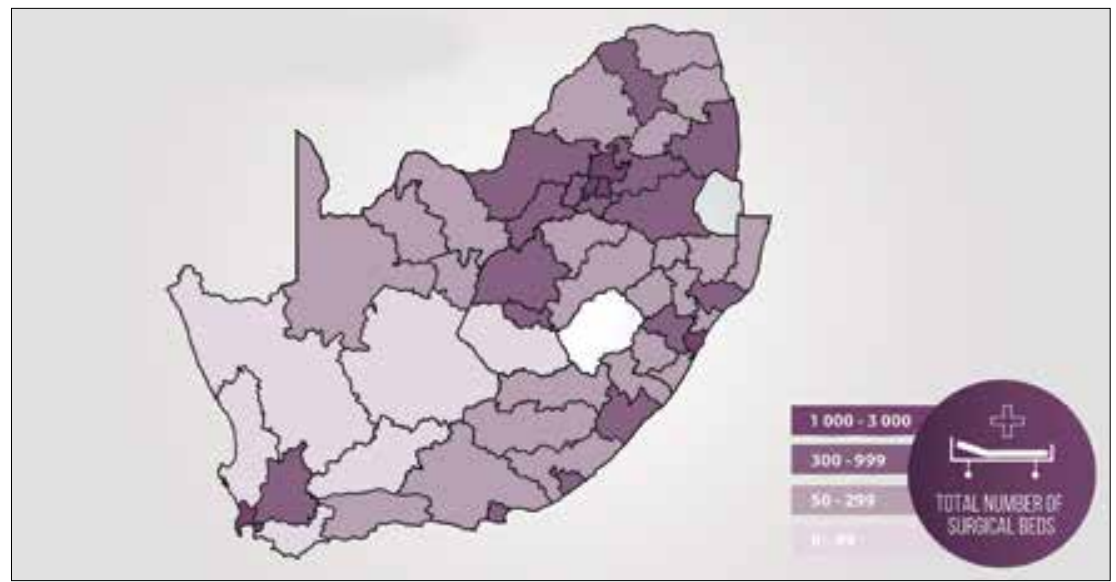

Fig. 3. Provincial distribution of total number of surgical beds in South Africa according to district municipality. 
tertiary-level hospitals. The majority of public hospitals were in EC $(n=75)$, although most of these were district-level hospitals. These were followed by KZN $(n=54)$, WC $(n=40)$, LP $(n=37)$ and FS $(n=30)$. The fewest public hospitals were in NW $(n=20)$ and NC $(n=17)$. There were no tertiary-level hospitals in NC and NW, with only 1 in FS. KZN ( $n=14)$ and GP $(n=11)$ had the largest number of regional hospitals (Table 1).

\section{Private hospitals}

The largest number of private hospitals were located in GP $(n=85)$, followed by WC $(n=34)$ and KZN ( $n=31)$ (Table 1$)$.

\section{Hospitals per 100000 population}

Hospitals per 100000 population were calculated for the total number of hospitals, although accessibility to private hospitals is limited to $\sim 16 \%$ of the population as part of the current health scheme in SA (Table 1). ${ }^{[10]}$

The largest total number of hospitals per population were in NC $(1.79 / 100000)$, FS (1.65/100 000) and EC (1.31/100 000). These provinces were regarded as being less well resourced. A comparison of public hospitals per 100000 uninsured population (84\% of SA) and private hospitals per 100000 insured population (16\% of SA) is shown in Table 2.
These results provide a more meaningful perspective. There were more private hospitals per insured population compared with public hospitals per uninsured population in all the provinces. The difference was greatest in FS and GP, and smallest in EC, LP and MP. GP had the fewest public hospitals per uninsured population $(0.27 / 100000)$, which fell far below the national average of $0.71 / 100000$.

\section{Total number of hospital beds}

There were an estimated 102229 hospital beds in SA. The provincial distribution of total hospital beds is shown in Fig. 2. The provincial distribution of the number of hospital beds according to hospital type is shown in Table 3.

GP had the largest overall number with 29181 beds, comprising almost equal numbers of public and private beds. The large number of public hospital beds was as a result of the 4 tertiary-level and 11 regional-level hospitals. These hospitals typically have more beds as per their definition. The smallest total number of hospital beds were in NC $(n=2015)$ and NW $(n=4877)$. These provinces had no central hospitals and very few private beds. The fewest private beds were in LP $(n=576)$ and NC $(n=361)$.

\section{Number of hospital beds per 100000 population}

The largest total number of beds per 100000 population were in GP $(n=225.95)$, followed by FS $(n=216.80)$ and KZN $(n=214.03)$

Table 1. Provincial distribution of total number of hospitals per 100000 population, 2014

\begin{tabular}{|c|c|c|c|c|c|}
\hline Province & Population, $n$ & Hospitals, $n$ & Private hospitals, $n$ & Public hospitals, $n$ & Total hospitals $/ 100000, n$ \\
\hline EC & 6786900 & 89 & 14 & 75 & 1.31 \\
\hline FS & 2786800 & 46 & 16 & 30 & 1.65 \\
\hline GP & 12914800 & 111 & 85 & 26 & 0.86 \\
\hline KZN & 10694400 & 85 & 31 & 54 & 0.79 \\
\hline LP & 5630500 & 45 & 7 & 37 & 0.80 \\
\hline MP & 4999300 & 40 & 12 & 28 & 0.80 \\
\hline NC & 1166700 & 21 & 4 & 17 & 1.79 \\
\hline NW & 3676300 & 34 & 14 & 20 & 0.92 \\
\hline WC & 6116300 & 74 & 34 & 40 & 1.21 \\
\hline SA & 54772000 & 544 & 217 & 327 & 1.00 \\
\hline
\end{tabular}

Table 2. Comparison of public and private hospitals per 100000 population, 2014

\begin{tabular}{|c|c|c|c|c|c|}
\hline Province & $\begin{array}{l}\text { Medical aid } \\
\text { coverage, } \%^{[11]}\end{array}$ & Public hospitals, $n$ & $\begin{array}{l}\text { Public hospitals } \\
\text { per } 100000 \\
\text { uninsured } \\
\text { population, } n\end{array}$ & Private hospitals, $n$ & $\begin{array}{l}\text { Private hospitals } \\
\text { per } 100000 \text { insured } \\
\text { population, } n\end{array}$ \\
\hline $\mathrm{EC}$ & 11.4 & 75 & 1.24 & 14 & 1.88 \\
\hline FS & 18.0 & 30 & 1.31 & 16 & 3.19 \\
\hline GP & 26.6 & 26 & 0.27 & 85 & 2.47 \\
\hline $\mathrm{KZN}$ & 12.5 & 54 & 0.58 & 31 & 2.32 \\
\hline LP & 8.7 & 37 & 0.71 & 7 & 1.43 \\
\hline MP & 13.3 & 28 & 0.64 & 12 & 1.80 \\
\hline NC & 15.4 & 17 & 1.71 & 4 & 2.29 \\
\hline NW & 13.7 & 20 & 0.63 & 14 & 2.78 \\
\hline WC & 25.5 & 40 & 0.87 & 34 & 2.16 \\
\hline SA & 16.0 & 327 & 0.71 & 217 & 2.48 \\
\hline
\end{tabular}


Table 3. Provincial distribution of hospital beds according to hospital type, $n$

\begin{tabular}{|c|c|c|c|c|c|}
\hline \multirow[b]{2}{*}{ Province } & \multicolumn{4}{|c|}{ Hospital } & \multirow[b]{2}{*}{ Total, $n$} \\
\hline & District, $n$ & Regional, $n$ & Central, $n$ & Private, $n$ & \\
\hline EC & 6252 & 555 & 4026 & 1684 & 12517 \\
\hline FS & 1568 & 1606 & 543 & 2325 & 6042 \\
\hline GP & 2722 & 6412 & 5721 & 14326 & 29181 \\
\hline $\mathrm{KZN}$ & 8399 & 8329 & 1359 & 4802 & 22889 \\
\hline LP & 4431 & 1579 & 1231 & 576 & 7817 \\
\hline MP & 3227 & 915 & 650 & 1382 & 6174 \\
\hline NC & 960 & 694 & 0 & 361 & 2015 \\
\hline NW & 1396 & 2016 & 0 & 1465 & 4877 \\
\hline WC & 2659 & 1172 & 2495 & 4391 & 10717 \\
\hline SA & 31614 & 23278 & 16025 & 31312 & 102229 \\
\hline
\end{tabular}

$\mathrm{EC}=$ Eastern Cape; FS = Free State; GP = Gauteng Province; KZN = KwaZulu-Natal; LP = Limpopo Province; MP = Mpumalanga Province; NC = Northern Cape; NW = North West; $\mathrm{WC}=$ Western Cape; $\mathrm{SA}=$ South Africa.

Table 4. Comparison of public hospital beds per uninsured population, private hospital beds per insured population and total hospital beds per total population, 2014

\begin{tabular}{|c|c|c|c|c|c|c|}
\hline Province & $\begin{array}{l}\text { Public hospital } \\
\text { beds, } n\end{array}$ & $\begin{array}{l}\text { Public hospital } \\
\text { beds per } 100000 \\
\text { uninsured } \\
\text { population, } n\end{array}$ & $\begin{array}{l}\text { Private } \\
\text { hospital beds, } n\end{array}$ & $\begin{array}{l}\text { Private hospital } \\
\text { beds per } \\
100000 \text { insured } \\
\text { population, } n\end{array}$ & Total beds, $n$ & $\begin{array}{l}\text { Total beds } \\
\text { per } 100000 \\
\text { population, } n\end{array}$ \\
\hline $\mathrm{EC}$ & 10833 & 179.34 & 1684 & 217.65 & 12517 & 184.43 \\
\hline FS & 3717 & 162.66 & 2325 & 463.49 & 6042 & 216.80 \\
\hline GP & 14855 & 155.44 & 14326 & 417.02 & 29181 & 225.95 \\
\hline KZN & 18087 & 192.19 & 4802 & 359.21 & 22889 & 214.03 \\
\hline LP & 7241 & 139.79 & 576 & 117.59 & 7817 & 138.83 \\
\hline MP & 4792 & 110.18 & 1382 & 207.85 & 6174 & 123.50 \\
\hline $\mathrm{NC}$ & 1654 & 166.79 & 361 & 200.92 & 2015 & 172.71 \\
\hline NW & 3412 & 106.68 & 1465 & 290.87 & 4877 & 132.66 \\
\hline WC & 6326 & 138.67 & 4391 & 281.54 & 10717 & 175.22 \\
\hline SA & 70917 & 154.14 & 31312 & 357.30 & 102229 & 186.64 \\
\hline
\end{tabular}

Table 5. Provincial distribution of surgical beds according to hospital type, $n$

\begin{tabular}{|c|c|c|c|c|c|}
\hline \multirow[b]{2}{*}{ Province } & \multicolumn{4}{|c|}{ Hospital } & \multirow[b]{2}{*}{ Total, $n$} \\
\hline & District, $n$ & Regional, $n$ & Central, $n$ & Private, $n$ & \\
\hline EC & 793 & 152 & 945 & 663 & 2553 \\
\hline FS & 559 & 336 & 60 & 764 & 1383 \\
\hline GP & 428 & 1176 & 848 & 4837 & 7289 \\
\hline KZN & 1670 & 1522 & 354 & 1459 & 4651 \\
\hline LP & 715 & 235 & 130 & 197 & 1277 \\
\hline MP & 605 & 132 & 107 & 406 & 1250 \\
\hline $\mathrm{NC}$ & 146 & 146 & 0 & 126 & 418 \\
\hline NW & 220 & 407 & 0 & 576 & 1203 \\
\hline WC & 455 & 210 & 509 & 1560 & 2734 \\
\hline SA & 5591 & 4316 & 2953 & 10578 & 22758 \\
\hline
\end{tabular}

EC = Eastern Cape; FS = Free State; GP = Gauteng Province; KZN = KwaZulu-Natal; LP = Limpopo Province; MP = Mpumalanga Province; NC = Northern Cape; NW = North West; $\mathrm{WC}=$ Western Cape; $\mathrm{SA}=$ South Africa. 
Table 6. Surgical beds per 100000 population according to sector and province, $n$

\begin{tabular}{|c|c|c|c|c|c|c|}
\hline Province & $\begin{array}{l}\text { Public hospital } \\
\text { surgical beds, } n\end{array}$ & $\begin{array}{l}\text { Public hospital } \\
\text { surgical beds } \\
\text { per } 100000 \\
\text { uninsured } \\
\text { population, } n\end{array}$ & $\begin{array}{l}\text { Private hospital } \\
\text { surgical beds, } n\end{array}$ & $\begin{array}{l}\text { Private hospital } \\
\text { surgical beds per } \\
100000 \text { insured } \\
\text { population, } n\end{array}$ & $\begin{array}{l}\text { Total surgical } \\
\text { beds, } n\end{array}$ & $\begin{array}{l}\text { Total surgical } \\
\text { beds per } 100000 \\
\text { population, } n\end{array}$ \\
\hline EC & 1890 & 31.29 & 663 & 85.69 & 2553 & 37.62 \\
\hline FS & 619 & 27.09 & 764 & 152.31 & 1383 & 49.62 \\
\hline GP & 2452 & 25.31 & 4837 & 140.80 & 7289 & 56.44 \\
\hline KZN & 3192 & 34.31 & 1449 & 108.39 & 4641 & 43.40 \\
\hline LP & 1080 & 20.85 & 197 & 40.22 & 1277 & 22.68 \\
\hline MP & 844 & 19.41 & 406 & 67.12 & 1250 & 25.00 \\
\hline $\mathrm{NC}$ & 292 & 29.10 & 126 & 70.13 & 418 & 35.83 \\
\hline NW & 627 & 19.83 & 576 & 114.36 & 1203 & 32.72 \\
\hline WC & 1174 & 25.39 & 1560 & 100.02 & 2734 & 44.70 \\
\hline SA & 12170 & 26.45 & 10578 & 120.70 & 22758 & 41.55 \\
\hline
\end{tabular}

The fewest beds per 100000 population were in MP $(n=123.50)$ and LP ( $n=138.83)$ (Table 4). There were far more private hospital beds per insured population $(n=357.30)$ than public hospital beds per uninsured population ( $n=154.14)$. The largest number of private beds per insured 100000 population were in FS ( $n=463.29)$, followed by GP $(n=417.02)$ and KZN $(n=359.21)$. The largest number of public sector beds available to uninsured patients per 100000 population were in KZN $(n=192.19)$, EC $(n=179.34)$, NC $(n=166.79)$ and FS $(n=162.66)$. These provinces comprise predominantly rural areas.

\section{Number of surgical beds}

In SA, 22758 beds were assigned as general surgical beds. Over half (53\%) of these were located in the public sector.

Both private and public surgical beds were concentrated in GP, WC and KZN. The largest number of private surgical beds were in GP, whereas the largest number of public surgical beds were in KZN (Fig. 3, Table 5).

The district-level hospitals had an average of 131 beds and 20 surgical beds compared with regional-level hospitals, which had an average of 471 beds and 86 surgical beds. Tertiary-level hospitals had an average of 762 beds and 144 surgical beds. Private hospitals had an average of 144 beds and 48 surgical beds.

In the public sector, surgical beds comprised $17.2 \%$ of total hospital beds, ranging between $14.9 \%$ (LP) and $26.7 \%$ (WC). In the private sector, surgical beds comprised $33.8 \%$ of the total beds, with a range of $29.3 \%$ (MP) - $39.4 \%$ (EC). Overall in SA, surgical beds comprised $22.3 \%$ of total hospital beds.

\section{Number of surgical beds per population}

There were 41.55 surgical beds per 100000 population, ranging from 22.68 (LP) to 56.44 (GP) (Table 6).

There was a striking difference between the number of surgical beds available to the public $(n=26.45)$ compared with the number available to private patients $(n=120.70)$. The fewest public beds per uninsured population were located in the less well-resourced provinces (MP, $n=19.41$; NW, $n=19.83$; and LP, $n=20.85$ ); however, these were not far behind the so-called well-resourced provinces (GP, $n=25.31$; and WC, $n=25.39$ ). Surprisingly, EC, which comprises largely rural districts, had the second highest number of surgical beds available to uninsured patients $(n=31.29)$ after KZN $(n=34.31)$. The largest number of private surgical beds available to patients with health insurance were in FS $(n=152.31), \mathrm{GP}(n=140.80)$ and NW $(n=114.36)$, whereas the fewest were in LP $(n=40.22)$ and MP $(n=67.12)$.

\section{Discussion}

Surgically treatable diseases comprise $>30 \%$ of the burden of disease globally. ${ }^{[6]}$ However, many people do not have access to adequate surgical care. Only $3.5 \%$ of the 243 million surgical procedures each year are performed in lower- and middle-income countries. ${ }^{[6]}$ The current research provided an assessment of surgical beds as a metric of surgical services, even though this does have limitations.

\section{Overview of national results in South Africa}

Our study included 544 hospitals in SA. There were 257 district-level hospitals, 49 regional-level hospitals and 21 tertiary-level hospitals. The district-level hospitals had an average of 131 beds and 20 surgical beds. The regional-level hospitals had an average of 471 beds and 86 surgical beds. The tertiary-level hospitals had an average of 762 beds and 144 surgical beds. EC, surprisingly, had the largest number of public hospitals, whereas the largest total number of hospitals per population were in NC, followed by FS and EC - despite these provinces being perceived as less well resourced.

The number of public hospitals per uninsured population for the country were 0.71 . GP fell far below this average with $0.27 / 100000$ However, GP had the third highest number of private hospitals per insured population $(n=2.47)$, behind NW $(n=2.78)$ and FS $(n=3.19)$. This was not surprising, as GP was by far the 'wealthiest' in terms of GDP, which was valued at ZAR811 billion (USD112 billion). ${ }^{[9]}$ When public and private facilities were combined $(n=0.86)$, GP still fell below the national average of 1.00 hospital per 100000 population.

\section{Hospital beds as resource indicators}

The largest proportion of the 102229 hospital beds were located in GP (28\%), KZN (22\%), EC (12\%) and WC (10\%). GP, WC and KZN comprise large metropolitan areas, whereas EC is largely rural. 
GP had the largest overall number of beds ( $n=29181$ ), comprising almost equal numbers of public and private beds. The reason for the large number of public hospital beds was the four tertiary-level and 11 regional-level hospitals in the province. Hospital beds per 100000 were greatest in the metropolitan areas, with the largest total number of beds per population in GP $(n=225.95)$, followed by FS $(n=216.80)$ and KZN ( $n=214.03)$. Despite WC having large metropolitan areas, it had fewer hospital beds per population $(n=175.22)$ than EC $(n=184.43)$. When private hospital beds per population were compared with public hospital beds, a far greater maldistribution was found. Unexpectedly, the largest number of public hospital beds available to uninsured patients were in the less well-resourced provinces in SA.

\section{Surgical beds}

When the number of surgical beds were compared across different levels of care, district-level hospitals reported a range of surgical beds from as few as 146 in NC to as many as 1670 in KZN. In all provinces, district-level surgical beds were more numerous than regional-level surgical beds; yet, most district-level facilities refer their surgical cases to regional facilities for treatment. In particular, KZN district-level hospitals were found to be performing very few surgical procedures, except caesarean sections. ${ }^{[12]}$ With far more surgical beds available at district-level facilities and the knowledge that surgery at this level is more cost-effective, ${ }^{[13]}$ there needs to be a greater emphasis on performing surgery at district level. This would involve ensuring that operating theatres were 'functional' and that well-qualified surgical, anaesthetic and nursing staff were available to perform the procedures. Tertiary-level surgical beds were most numerous in EC $(n=945)$, followed by GP $(n=848)$ and WC $(n=509)$.

\section{Total number of hospital and surgical beds in the private sector}

Private hospitals had an average of 144 beds and 48 surgical beds. Netcare, Life, Mediclinic and independent groups were the largest private hospital groups. There were 31312 private hospital beds in SA. The largest proportion of these were in GP $(n=14326)$, KZN $(n=4802)$ and WC $(n=4391)$.

Private beds comprised $31 \%$ of total hospital beds in SA, which was a substantial increase from the $21 \%$ reported in 2006. ${ }^{[10]}$ Forty-six percent of private beds were located in the most populous province, i.e. GP. There were 10578 general surgical beds in the private sector. The largest number of private surgical beds were in GP $(n=4837)$, WC ( $n=1560)$ and KZN ( $n=1449)$. GP had three times as many surgical beds than other metropoles, such as WC and KZN. With its significant contribution to the national GDP, this was not surprising. MP had the fewest private surgical beds as a proportion of total number of beds (29.3\%), and EC and NW had the largest proportion, with 39.3\% each. In SA, private hospitals allocate approximately one-third of total hospital beds to surgical patients, whereas public hospitals allocate 15 $-26 \%$ of their beds to general surgery.

Rural provinces, such as EC, have a significant migration of patients towards the urban provinces (such as WC) in search of better healthcare, despite having a larger number of hospitals. This suggests that the number of resources may not reflect acceptable levels of care and provinces with fewer hospitals may have higher patient volumes. Despite the perception that WC and GP were 'wealthy' and had greater resources, they were often accessed by inhabitants of neighbouring provinces, thereby placing strain on the health systems. By implication, simply looking at the number of hospitals and beds does not translate into adequate healthcare or surgical provision, as bed utilisation rates are highest in these provinces. WC experienced a bed utilisation rate of 88.7, which is far higher than the national average of 68.3 and that of EC, which has a bed utilisation rate of 59.5 (the lowest on the country). ${ }^{[1]}$ Furthermore, WC reported an average length of hospital stay of 3.7 days, whereas $\mathrm{EC}$ reported an average of 5.7 days. ${ }^{[1]}$ This could be as a result of greater patient volumes in WC, which may result in mandatory higher patient turnover because of 'bed pressure'. Assessing readmission rates to hospital could provide an indication as to whether this higher turnover rate results in poorer outcomes and increased expenditure.

Tracking the migration patterns of patients may provide insight into their help-seeking behaviour. Migration is an important demographic process that shapes the distribution of the provincial population. ${ }^{[8]}$ From 2011 to 2016, it was estimated that 241758 people migrated from EC; LP was estimated to experience an outflow of $~ 303101$ migrants. During the same period, GP and WC were estimated to experience an inflow of $\sim 1106375$ and 344830 migrants, respectively. MP and NW also received a positive net migration, whereas EC, FS and LP experienced the largest outflow. ${ }^{[8]}$ Understanding the ebb and flow of patients migrating between provinces in search of healthcare is critical and demonstrates that using infrastructure metrics, such as the number of hospitals and beds, is limited in the information provided to policymakers about resource availability.

There is unfortunately no uniform reporting of hospital beds, as countries use different definitions for the number of hospital beds. Nonetheless, since the 1990s, there has been a worldwide decrease in the number of beds. ${ }^{[14]}$ SA has 186 hospital beds per 100000 population, whereas according to the World Bank, Australia has the highest number, with 382 beds per 100000 population. The UK (294/100 000) and USA (299/100 000) have $60 \%$ more hospital beds per population than SA. Brazil is an upper-middle-income country, with $~ 230$ hospital beds per $100000 .^{[14]}$ Kenya and Zambia are classified as low- and middle-income countries and have 140 and 190 hospital beds per 100 000, respectively. ${ }^{[14]}$ Uganda, Tanzania and Mozambique have the fewest beds per population, indicating limited resources that coincide with being low-income countries. Surgical beds are currently not used as a measure of surgical resources and no global data exist as a comparative for SA's 41.55 surgical beds per 100000 . This could be as a result of surgical bed numbers being poor indicators of surgical capacity.

\section{Study limitations}

The measurement of the total number of beds had its shortcomings, as not all hospitals were included in the study. Specialised hospitals were excluded, as they did not perform general surgical procedures. District-level hospitals were non-uniform in the manner in which they allocated and reported surgical beds. The use of metrics for describing hospital beds as an indicator of provision of surgical care is flawed. Perhaps bed utilisation rates would provide more robust data. The proportion of patients with health insurance and access to the private sector may not represent the true number of patients who access private care. There are a number of uninsured patients who can afford out-of-pocket payments, which predisposes them to catastrophically high health expenditure. Similarly, patients with insurance may choose to access public sector hospitals.

\section{Conclusion}

Diseases that require surgery are an important and growing public health priority. Strengthening surgical systems will allow countries to tackle and reduce the surgical burden of disease, which may improve health outcomes globally. Our research provides part of an overview of the surgical infrastructure in SA and highlights some limitations of using these metrics to evaluate surgical capacity. 
Acknowledgements. We wish to acknowledge the University of Cape Town. Author contributions. AJD: collection, analysis and interpretation of the data, as well as drafting of the article. DK: critical revision of the article and final approval of the manuscript.

Funding. None.

Conflicts of interest. None.

1. Ozgediz D, Jamison D, Cherian M, McQueen K. The burden of surgical conditions and access to surgical care in low- and middle-income countries. Bull World Health Organ 2008;86(8):646-647. .

2. Bickler S, Ozgediz D, Gosselin R, et al. Key concepts for estimating the burden of surgical conditions and the unmet need for surgical care. World J Surg 2010;34(3):372-380. https://doi.org/10.1007/s00268-009-0261-6 3. Luboga S, Galukande M, Mabweijano J, Ozgediz D, Jayaraman S. Key aspects of health policy development to improve surgical services in Uganda. World J Surg 2010;34(11):2511-2517. https://doi. org/10.1007/s00268-010-0585-2

. Ozgediz D, Riviello R. The 'other' neglected diseases in global public health: Surgical conditions in subSaharan Africa. PLoS Med 2008;5(6):e121. https://doi.org/10.1371/journal.pmed.0050121

5. Weiser TG, Regenbogen S, Thompson K, et al. An estimation of the global volume of surgery: A modelling strategy based on available data. Lancet 2008;372(9633):139-144. https://doi. org/10.1016/S0140-6736(08)60878-8
6. Meara JG, Leather AJM, Hagander L, et al. Global surgery 2030: Evidence and solutions for achieving health, welfare, and economic development. Lancet 2015;386(9993):569-624. https://doi.org/10.1016 S0140-6736(15)60160-

7. Provincial Government. http://www.southafrica.info/about/government/govprov (accessed 25 Octobe 2017)

8. Statistics South Africa. Annual 2013/2014 report. www.statssa.gov.za (accessed 25 October 2017).

9. World Bank. South African overview. 2015. www.worldbank.org (accessed 25 October 2017).

10. Matsebula T, Willie M. Private hospitals. In: Harrison S, Bhana R, Ntuli A, eds. South African Health Review 2007. Durban: Health Systems Trust, 2007:159-164.

11. Massyn N, Day C, Peer N, Padarath A, Barron P, English R, eds. District Health Barometer. 2013/2014 Durban: Health Systems Trust, 2014

12. Clarke D, Kong V, Handley J, Aldous C. A concept paper: Using the outcomes of common surgical conditions as quality metrics to benchmark district surgical services in South Africa as part of a systematic quality improvement programme. S Afr J Surg 2013;51(3):84-86. https://doi.org/10.7196/sajs.1476

13. Chao T, Sharma K, Mandigo M, et al. Cost-effectiveness and its policy implications for global health: A systematic review and analysis. Lancet Glob Health 2014;2(6):e334-e345. https://doi.org/10.1016/ S2214-109X(14)70213-X

14. World Bank. Hospital beds per capita. 2014. www.worldbank.org (accessed 25 October 2017). 